\title{
Inlay butterfly versus underlay cartilage tympanoplasty
}

\author{
Osama Hassan* ${ }^{*}$, Mena Esmat, Mohamed Salah and Mohamed El Shazly
}

\begin{abstract}
Background: Tympanic membrane grafting is one of the most common otological procedures. Underlay technique of tympanoplasty was described by Shea in 1960. Utech in 1959 introduce the cartilage in middle ear surgery. The search for an ideal graft material and technique for tympanoplasty was adopted by numerous contributions from surgeons all over the world. Professor Roland Eavey in 1998 introduced a transcanal inlay technique which offers advantages of surgical ease and speed as well as patient comfort.

Results: This study included 46 patients; 23 patients had inlay butterfly myringoplasty (group A), and 23 patients had underlay cartilage tympanoplasty. In group A, $65 \%$ of the patients had a completely healed tympanic membrane postoperatively. Mean AB gap closure was $3.94 \mathrm{db}$. In underlay group B, 82.6\% of the patients had a completely healed tympanic membrane postoperatively. Mean AB gap closure was $4.7 \mathrm{db}$. These outcomes show no statistically significant difference between both groups in terms of graft take and hearing improvement $(p>0.1)$.

Conclusions: Inlay butterfly myringoplasty is an easy, reliable, and time saving procedure that should be possible as a choice to underlay procedure. Results are comparable with underlay technique in terms of graft take rate and hearing improvement. Procedure is better regarding diminishing operative time, postoperative pain, and duration before resuming usual activities.
\end{abstract}

Keywords: Myringoplasty, Underlay, Inlay, Cartilage tympanic membrane perforation

\section{Background}

Myringoplasty is a surgical closure of the ear drum without the manipulation of the ossicles or middle ear cavity, while tympanoplasty consists of further getting access to the middle ear space and eradication of the disorder if present [1].

Medial grafting (underlay) and lateral grafting (overlay) are 2 primary strategies. These phases describe the location of the graft with regard to the central fibrous layer and annulus of the tympanic membrane [2].

Underlay tympanoplasty is a particularly faster and simpler approach than overlay. It has much less incidence of graft anterior blunting and lateralization [3].

*Correspondence: oshassan75@gmail.com

Department of Otorhinolaryngology, Kasr Alainy School of Medicine, Cairo University, Cairo, Egypt
Temporalis fascia and cartilage are the most typically used grafting substances for ear drum. Cartilage become first introduced in middle ear surgical operation via Utech in 1959 [4]. It began to replace fascia over the past many years because it is far less susceptible to retraction and perforation because of its stiffness and rigidity $[5,6]$.

Transcanal inlay cartilage butterfly graft approach was introduced by Professor Roland Eavey in 1998, which had the benefits of surgical ease and speed as well as patient comfort. This technique yielded high-quality graft take rates and hearing results without enormous postoperative complications [7].

\section{Aim of the work}

The aim of the work is as follows: to compare the inlay butterfly cartilage myringoplasty as opposed to underlay cartilage tympanoplasty in particular in phases of 
the graft take rate and hearing outcome for cases of central tympanic membrane perforation.

\section{Methods}

\section{Ethics and consent to participate}

This study was approved by the ethics committee of Otorhinolaryngology Department, Cairo University, with unavailable approval number. Informed written consent to participate in the study was provided by all participants' parent or legal guardian in the case of children under 16 years old.

This is a prospective analytical study in which contributors with dry central tympanic membrane perforations presented throughout the period from 2017 to 2018 who had either inlay butterfly cartilage myringoplasty or underlay cartilage tympanoplasty were recruited and analyzed. We excluded cases with previous myringoplasty, cases with total perforation, and other techniques of tympanic membrane grafting.

All patients had been subjected to detailed history taking, full ENT exam, and otoscopic and ear endoscopic examination to evaluate the size and location of the perforation which is classified to the following: "small perforation" $<3 \mathrm{~mm}(<25 \%$ of TM surface area), "medium sized" 3-5 mm (25-50\%), and "large perforation" > five $\mathrm{mm}(>50 \%)[8,9]$. Audiological evaluation was performed by means of pure tone and speech audiometry.

This study included forty six patients. They have been divided into 2 groups according to treatment modality which become chosen according to surgeon preference:

Group A included 23 patients who had transcanal technique inlay butterfly approach using tragal cartilage combined with perichondrium on one side for tympanic membrane perforation grafting (Fig. 1).

Surgical steps:

- Edges of the perforation refreshed using Rosen needle and a crocodile forceps.

- Meatal surface of tragus is injected with 1 to $3 \mathrm{ml}$ of mixture of saline adrenaline $(1: 200,000)$ solution.
- Tragal cartilage covered with perichondrium is harvested using No 15 surgical blade and small sharp scissors.

- Dimensions and size of perforation are estimated by the use of right angled needle or piece of sterile paper.

- Tragal cartilage is refashioned $2 \mathrm{~mm}$ wider than the size of perforation.

- No 11 surgical blade is used to incise the edge of the cartilage between the two perichondrial surfaces, developing $1 \mathrm{~mm}$ deep groove.

- Cartilage is inserted via the perforation, one wing medial and the other lateral to the edge of perforation.

- Numerous small pieces of self-absorbed gel foam are positioned in the external canal. Similarly, small piece of gelfoam can be placed inside the middle ear medial to the graft if not fitting properly in its place.

- Small ear pack impregnated with antibiotic ointment is inserted into the external canal.

- Tragal incision is closed with silk 3/0 simple interrupted sutures.

Group B included 23 patients who had transcanal technique underlay tragal cartilage slice tympanoplasty.

Surgical technique:

- Refreshment of perforation and harvesting of tragal cartilage were done like the preceding approach.

- Round knife is used to make a transverse incision inside the posterior ear canal skin from 12 o'clock to 6 o'clock $2 \mathrm{~mm}$ lateral to the annulus.

- The posterior meatal skin flap is elevated from the underlying bone using Fisch microraspatory, until the tympanic annulus is reached which is then dissected with the remnant of the tympanic membrane and reflected anteriorly.

- The tragal cartilage graft is positioned medial to the handle of malleus, and the tympanomeatal flap is returned again.

- Several small portions of self-absorbed gel foam are positioned in the external canal.
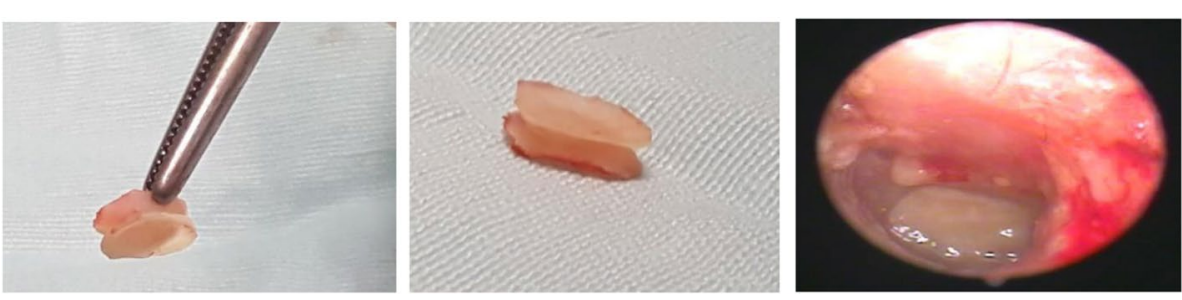

Fig. 1 Preparation and positioning of inlay butterfly tragal cartilage 
- Ear pack impregnated with antibiotic ointment is inserted into the external canal, and bandage is applied to the operated ear.

- Tragal incision is closed by silk 3/0 simple interrupted sutures.

All cases were advised postoperatively to keep the ears dry and avoid straining and constipation. Oral antibiotics and analgesics had been prescribed 1 week postoperatively in addition to local antibiotics drops for another 1 week for all patients. Follow-up was performed after 1 and 2 weeks and 1 and 3 months post-operatively by means of history taking, otoscopic, and endoscopic ear examination for the assessment of graft take and presence of any complications. Take rate became assessed and classified as complete take or partial take and complete loss of the graft.

Audiological evaluation was carried out with pure tone and speech audiometry 3 months post-operatively through calculating the close of the air-bone gap.

Post-operative pain was recorded with the use of visible analog scale. It was assessed subjectively via the patient through a scale from 1 to 10 .

\section{Results}

After exclusion of other techniques of myringoplasty, this research included 46 patients. Twenty-three patients had inlay butterfly myringoplasty (group A); 23 patients who had underlay cartilage tympanoplasty are in group B.

The mean follow-up duration for both groups is 3.41 months.

In group A, 15 patients (65\%) had a completely healed tympanic membrane postoperatively, and 4 patients (17\%) had a partially (almost 50\%) healed tympanic membrane postoperatively; on the other hand, four patients ( $17 \%$ of the patients) had a complete loss of the graft at the end of the follow-up period (Table 1).

In group B, 19 patients ( $82.6 \%$ of the cases) had a totally healed tympanic membrane postoperatively, while 4 patients ( $17.4 \%$ of the patients) had a complete loss of the graft postoperatively at the end of the study up period (Table 1).

The difference among each group regarding graft take rate and closure of perforation was not statistically significant (Table 1).

Concerning hearing improvement, in group $\mathrm{A}$, the mean preoperative $A B$ gap was $18.53 \mathrm{db}$, while the mean [3-]month postoperative $A B$ gap was $14.59 \mathrm{db}$ which became a statistically significant improvement (Table 2).

At the same time as in group $B$, the mean preoperative $A B$ gap was $22.61 \mathrm{db}$, and the mean 3 month postoperative $A B$ hole is $17.91 \mathrm{db}$, which was also statistically significant (Table 3).

In group A, 16 patients (69.6\%) experienced hearing improvement (i.e., decrease within $A B$ gap), while 7 patients (30\%) had no hearing improvement postoperatively; in group B, 19 patients (82.6\%) experienced hearing improvement, and 4 patients $(17.4 \%)$ had no hearing improvement postoperatively. The difference among the 2 groups turned into not statistically significant in terms of hearing improvement (Fig. 2).

Numerous factors which could have an effect on the take of the graft had been studied additionally, which includes age of the affected person (patients included ranged from 15 to 60 years old), site of the perforation, and condition of EAC, either wide and straight or narrow and convoluted. The study confirmed no

Table 1 Comparison between tympanic membrane healing results in both groups

\begin{tabular}{|c|c|c|c|c|c|c|}
\hline & & \multicolumn{4}{|l|}{ Group } & \multirow{3}{*}{$p$ value } \\
\hline & & \multicolumn{2}{|c|}{ Group A } & \multicolumn{2}{|c|}{ Group B } & \\
\hline & & Count & $\%$ & Count & $\%$ & \\
\hline \multirow[t]{3}{*}{ Graft take } & Partial (50\%) & 4 & 17.5 & 0 & 0 & 0.149 \\
\hline & Complete take & 15 & 65 & 19 & 82.6 & \\
\hline & Complete loss & 4 & 17.5 & 4 & 17.4 & \\
\hline
\end{tabular}

Table 2 Comparison between preop. and postop. AB gap in group A

\begin{tabular}{|c|c|c|c|c|c|c|}
\hline & \multicolumn{5}{|c|}{ Group A } & \multirow[t]{2}{*}{$p$ value } \\
\hline & Mean & SD & Median & Minimum & Maximum & \\
\hline Preop. AB gap (db) & 18.53 & 6.56 & 15.00 & 10.00 & 30.00 & 0.001 \\
\hline Postop. AB gap (db) & 14.59 & 7.73 & 15.00 & 5.00 & 30.00 & \\
\hline
\end{tabular}


Table 3 Comparison between preop. and postop. AB gap in group B

\begin{tabular}{llllll}
\hline & \multicolumn{2}{l}{ Group B } & & & \multicolumn{1}{c}{$\boldsymbol{p}$ value } \\
\cline { 2 - 6 } & Mean & SD & Median & Minimum & Maximum \\
\hline Preop. AB gap $(\mathrm{db})$ & 22.61 & 4.49 & 25.00 & 15.00 & 30.00 \\
Postop. AB gap $(\mathrm{db})$ & 17.91 & 4.43 & 18.00 & 10.00 & 25.00 \\
\hline
\end{tabular}
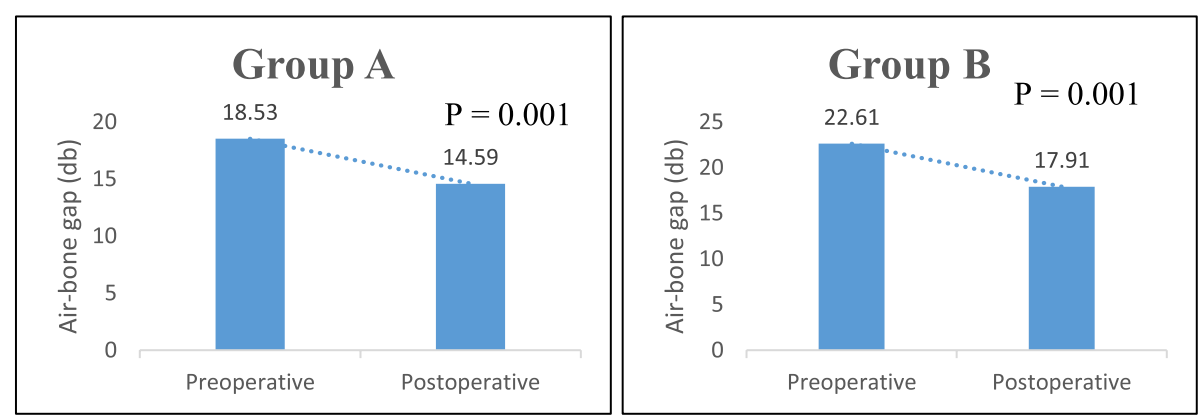

Fig. 2 Comparison between mean preop. and 1-month postop. AB gap for groups A and B

statistically significant relation among these elements and take of the graft in both groups.

In group $\mathrm{A}$, the mean operative time was $50.88 \mathrm{~min}$; on the other side, in group $\mathrm{B}$, the mean operative time was $110.87 \mathrm{~min}$. Operative time became significantly decreased in group A than in group B.

Postoperative pain was studied with the use of visual analog score. In group $\mathrm{A}$, the mean postoperative pain score was 1.59 , and the average duration before resuming normal life was 3 days. In group B, the mean postoperative pain score was 3.91, and the average length before resuming usual activities was 6.39 days.

Postoperative pain and period before resuming common activities were considerably decreased in group A than in group B.

Postoperative middle ear infection took place in 2 patients in group A and in one patient in group B. Both had been treated with systemic and local antibiotics; however, the graft was lost.

One patient in group A had otomycosis of EAC and was treated with local mopping and antifungal ear drops and resolved after 2 months, without affecting the take of the graft.

\section{Discussion}

Utech in 1959 was the first to introduce cartilage in middle ear surgical procedure. Cartilage has begun to replace fascia over the past decades [4]. It has been used with many modifications with more than 23 types described with the aid of Mirko Tos [10].
Cartilage grafts are much less liable to retraction and perforation, but there are some doubts regarding acoustic outcomes [11]. Latest research failed to reveal any statistical difference in postoperative hearing when cartilage is compared to fascia or perichondrium as grafting material in tympanoplasty [5].

Many research found out no significant difference between cartilage grafting and temporalis fascia grafting concerning graft take rates and hearing improvements rate, although some suggested that cartilage graft had a slightly high incidence in take rate, postoperative hearing, and air bone gap closure $[12,13]$.

Professor Roland Eavey in 1998 brought a transcanal inlay technique which offers benefits of surgical ease and velocity as well as affected person consolation [7]. He studied 9 children, with small- to medium-sized perforations. Complete closure of the tympanic membrane became performed in all cases. Pure tone averages improved from 5 to $20 \mathrm{db}$, with a median of $12 \mathrm{db}$. No good sized postoperative headaches occurred [7].

Dr. Eavey stated benefits for his new technique to be transcanal, less anesthesia time, no need for EAC packing, better immediate postoperative hearing, and rapid return to work and activities [7].

Our current study covered 40 patients, divided into 2 equal groups: group A, who underwent inlay butterfly myringoplasty, and group $\mathrm{B}$, who underwent underlay cartilage tympanoplasty.

Nineteen patients in group A $(82.6 \%)$ had a healed tympanic membrane postoperatively (11 complete closure and 3 partial closure); on the other hand, in group 
B, 19 patients (82.6\% of the patients) had a totally healed tympanic membrane postoperatively. The difference between both groups was not statistically significant ( $p$ $=0.149$ ). Take rates in each group are similar with other researches.

Eavey's inlay butterfly myringoplasty technique became used by many authors; Lubianca-Neto in 2001 studied 20 adult cases with a graft take rate of $90 \%$ [14]; Anand et al. in 2002 additionally operated 20 patients with a graft take rate of 90\% [15]; Wang and Lin in 2008 operated fortyeight ear with a closure rate of $85 \%$ [16]; Alain et al. in 2016 operated 33 cases with total, subtotal, and annular, and the graft take rate was $94 \%$ [17].

In literatures, graft take rate for underlay cartilage tympanoplasty ranged between 91 and $98 \%[18,19]$.

In this study, the mean $A B$ gap closure in group $A$ after 3 months was $3.94 \mathrm{db}$, while in group $\mathrm{B}$, the mean $\mathrm{AB}$ gap closure was $4.7 \mathrm{db}$. The difference between the two groups was not statistically significant; outcomes are comparable however barely less than other researches. This may be because of the incredibly short followup period in our study, and pure tone audiometry was carried out 3 months postoperatively, while in most researches, it was performed 6 months postoperatively.

For inlay butterfly myringoplasty, the mean air bone gap closure was $12 \mathrm{db}$ for Eavey in 1998 [7], $15 \mathrm{db}$ for Anand et al. in 2002 [15], $6.3 \mathrm{db}$ for Wang and Lin in 2008 [16], and $27.1 \mathrm{db}$ for Alain et al. in 2016; this big improvement in this study was due to the large average preoperative $\mathrm{AB}$ gap being implied mainly for total and subtotal eardrum perforations [17].

In literatures, mean $\mathrm{AB}$ gap closure for underlay cartilage tympanoplasty ranged between 9 and $12 \mathrm{db}[18,19]$.

In our study, the operative time was significantly reduced in group A than in group B $(p<0.001)$.

Postoperative pain and duration before resuming regular activities were significantly reduced in group A than in group $\mathrm{B}(p<0.001)$; that was because in group $\mathrm{B}$, the operative technique included 2 incisions: one for tragal cartilage harvesting and the other for elevating tympanomeatal skin flap which add some morbidity to the technique.

The limitation of our study is the relatively short duration of follow-up and exclusion of cases with total and subtotal ear drum perforations. A longer follow-up of up to 1 year would further validate the findings of the study.

\section{Conclusions}

Inlay butterfly myringoplasty is reliable as an easy and time saving technique that can be carried out in cases with eardrum perforations as an alternative to underlay approach. Outcomes are comparable with underlay technique in terms of take rate and hearing improvement.
Postoperative pain and duration before resuming normal activities are significantly less with the inlay approach.

\section{Abbreviations}

TM:Tympanic membrane; HL: Hearing loss; EAC: External auditory canal; AB: Air bone.

\section{Acknowledgements \\ Not applicable}

\section{Authors' contributions}

All the authors have read and approved the manuscript. $\mathrm{OH}$ (corresponding author) shared in interpreting and writing the paper. ME shared in the data collection, writing, statistics, and drafting. MS shared in the substantial contributions to the conception and interpretation. MEl shared in revising the manuscript and general guidance throughout the work.

Funding

No funding was provided for this study.

Availability of data and materials

All data and materials are available to be shared

\section{Declarations}

Consent of publication

Not applicable.

\section{Competing of interests}

The authors declare that they have no competing interests.

\section{Ethics approval and consent to participate}

All procedures performed in this study were in accordance with the ethical standards of the research committee of ENT department, Cairo University, Egypt.

Reference number is not available.

Informed written consent to participate in the study was provided by all participants' parent or legal guardian in the case of children under 16 years old.

Received: 12 March 2021 Accepted: 6 October 2021

Published online: 30 October 2021

\section{References}

1. Sarkar S (2013) A review on the history of tympanoplasty. Ind J Otolaryngol Head Neck Surg 65(Suppl 3):455-460

2. Mudry A (2005) History of tympanoplasty. Otol Neurotol 26(3):554-555

3. Gersdorff M, Gerard JM, Thill MP (2003) Overlay versus underlay tympanoplasty. Comparative study of 122 cases. Rev Laryngol Otol Rhinol 124(1):15

4. Utech H (1959) Tympanotomy in disorders of sound conduction; its diagnostic \& therapeutic possibilities. Z Laryngol Rhinol Otol 38(4):212

5. Dornhoffer JL (2003) Cartilage tympanoplasty: indications, techniques, and outcomes in A 1,000-patient series. Laryngoscope 113(11):1844-1856

6. Khan MM, Parab SR (2011) Primary cartilage tympanoplasty: our technique and results. Am J Otolaryngol 32(5):381-387

7. Eavey RD (1998) Inlay tympanoplasty: cartilage butterfly technique. Laryngoscope 108(5):657-661

8. Hsu CY, Chen YS, Hwang JH, Liu TC (2004) A computer program to calculate the size of tympanic membrane perforations. Clin Otolaryngol Allied Sci 29:340-2

9. Saliba I, Abela A, Arcand P (2011) Tympanic membrane perforation: size, site and hearing evaluation. Int J Pediatr Otorhinolaryngol 75:527-31

10. Yung M (2008) Cartilage tympanoplasty: literature review. J Laryngol Otol 122(7):663-672 
11. Onal K, Arslanoglu S, Songu M, Demiray U, Demirpehlivan IA (2012) Functional results of temporalis fascia versus cartilage tympanoplasty in patients with bilateral chronic otitis media. J Laryngol Otol 126(1):22-25

12. Sozen E, Ucal YO, Tansuker HD, Coskun BU, Korkut AY, Dadas B (2012) Is the tragal cartilage necessary for type 1 tympanoplasties? J Craniofac Surg 23(4):e280-e283

13. Lubianca-Neto JF (2000) Inlay butterfly cartilage tympanoplasty (Eavey technique) modified for adults. Otolaryngol Head Neck Surg 123(4):492-494

14. Anand TS, Kathuria G, Kumar S, Wadhwa V, Pradhan T (2002) Butterfly inlay tympanoplasty: a study in Indian scenario. Ind J Otolaryngol Head Neck Surg 54(1):11-13

15. Wang WH, Lin YC (2008) Minimally invasive inlay and underlay tympanoplasty. Am J Otolaryngol 29(6):363-366

16. Alain H, Esmat NH, Ohad H, Yona V, Nageris BI (2016) Butterfly myringoplasty for total, subtotal, and annular perforations. Laryngoscope 126(11):2565-2568
17. Chhapola S, Matta I (2012) Cartilage-perichondrium: an ideal graft material? Ind J Otolaryngol Head Neck Surg 64(3):208-213

18. De Seta E, De Seta D, Covelli E, Viccaro M, Filipo R (2013) Type I tympanoplasty with island chondro-perichondral tragal graft: the preferred technique? J Laryngol Otol 127(4):354-358

19. Haksever M, Akduman D, Solmaz F, Gundogdu E (2015) Inlay butterfly cartilage tympanoplasty in the treatment of dry central perforated chronic otitis media as an effective and time-saving procedure. Eur Arch Otorhinolaryngol 272(4):867-872

\section{Publisher's Note}

Springer Nature remains neutral with regard to jurisdictional claims in published maps and institutional affiliations.

\section{Submit your manuscript to a SpringerOpen ${ }^{\circ}$ journal and benefit from:}

- Convenient online submission

- Rigorous peer review

- Open access: articles freely available online

- High visibility within the field

Retaining the copyright to your article

Submit your next manuscript at $\boldsymbol{\nabla}$ springeropen.com 